\title{
Teaching Water Quality Analysis using a constructed wetlands microcosm in a Non-Science Majors Environmental Science Laboratory
}

\author{
Aelin Shea ${ }^{1}$, Christy R. Violin ${ }^{2}$, Christina Wallace ${ }^{1}$, Brian Michael Forster ${ }^{1 *}$ \\ ${ }^{1}$ College of Arts \& Sciences, Saint Joseph's University, Philadelphia, PA 19131, USA \\ ${ }^{2}$ Environmental Science and Sustainability Program, Saint Joseph's University, Philadelphia, PA 19131, USA
}

*Corresponding Author: bforster@sju.edu

Citation: Shea, A., Violin, C. R., Wallace, C. and Forster, B. M. (2019). Teaching Water Quality Analysis using a constructed wetlands microcosm in a Non-Science Majors Environmental Science Laboratory. Pedagogical Research, 4(4), em0046. https:/ / doi.org/10.29333/pr/5945

Published: September 28, 2019

\begin{abstract}
Wetlands are defined as areas of soil saturated with standing water. These areas are rich in biodiversity, containing numerous plants, animals and microorganisms. Wetlands act as natural filtering systems for runoff and can improve the water quality in an area. To demonstrate the importance of wetlands to a nonscience major introductory environmental science class, we designed a small freshwater wetland filter. This filter is able to reduce the amount of ammonia present in water entering the system. Sequencing the bacteria present in the soil of the filter identified bacteria capable of performing anaerobic ammonium oxidation (anammox). In this paper, we describe how to construct the filter and use it during class. It is our goal that this filter gives students a better appreciation of the role wetland ecosystems play in maintaining water quality.
\end{abstract}

Keywords: laboratory demonstration, nature of science, water quality, non-science majors, wetlands, microcosm, filtration, anammox bacteria

\section{INTRODUCTION}

Science classes designed as non-science major service courses should relate the importance of science to everyday life (Smith et al., 2004). One of the non-science majors' laboratory-based courses we offer at our university is an introductory environmental science course. This course covers current environmental concerns including climate change, renewable energy sources, biodiversity loss, and water quality, quantity and geographic distribution. Connecting in-class activities with the natural world they represent is an important component of environmental science education (Ernst and Theimer, 2011).

Water quality is a global environmental concern, with social and economic impacts (United Nations, 2012). Widespread degradation of coastal and freshwater resources occurs due to nutrient and pollutant loading from upstream urban and agricultural environments through both point and non-point sources (Paul and Meyer, 2001). In turn, water quality impairment can affect biodiversity, human health, and food safety and security (Roy et al., 2003), Surface water pollutants can also enter groundwater, causing aquifer contamination, subsurface, dispersal, and long-term pollutant retention (Pavlidis and Tsihrintzis, 2018). Nitrogen and phosphorus containing compounds are components of commercial fertilizers, sewage, and livestock waste. Excess of these nutrients in runoff can lead to phenomena such as eutrophication (Smith et al., 1999), red tides (Lee et al., 2007) and anoxic dead zone development (Joyce, 2000). One type of nitrogen pollutant is ammonia. This pollutant can enter water through industrial discharge, agricultural runoff and from the nitrogenous wastes of animals (US EPA, 2019). Ammonia in water can exist either as $\mathrm{NH}_{3}$ (ammonia) or as $\mathrm{NH}_{4}^{+}$(ammonium ion) (Ip et al., 2001). High levels of 


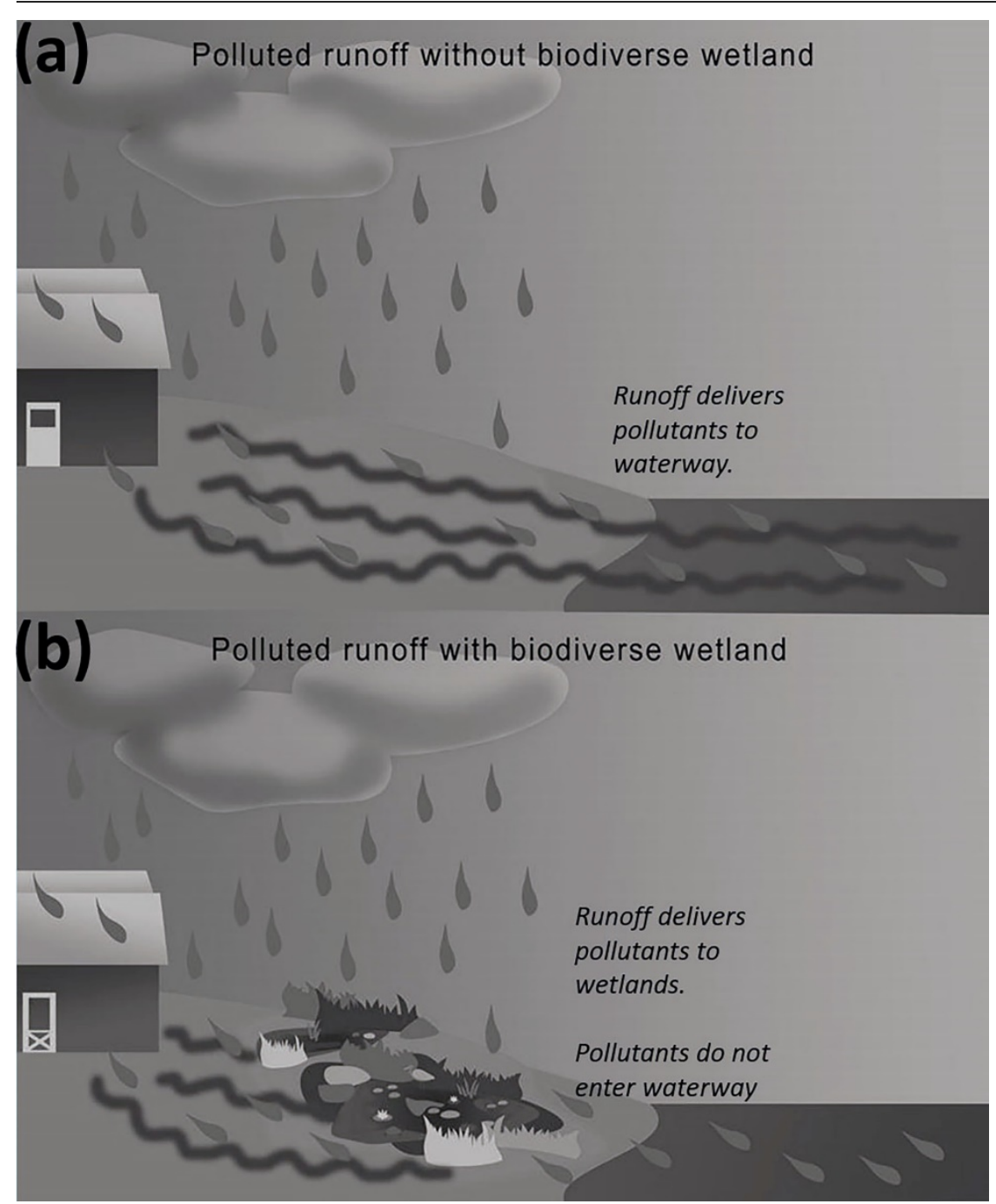

Figure 1. Importance of wetlands for water quality. (a) In areas lacking wetlands, pollutants on the ground will be picked up by runoff (squiggly line) and delivered to waterways. (b) In areas containing wetlands, pollutants on the ground will be picked up by runoff and delivered to the wetlands. Plants and microorganisms present in the wetlands can reduce the amount of pollutants entering waterways. Figure adapted from http://techalive.mtu.edu/meec/module12/Chemicalfunctionsofwetlands.htm

ammonia can negatively affect several plants and aquatic animals (Ip et al., 2001; Pearson and Stewart, 1993; van der Eerden, 1982).

Water pollutants can be removed via human-directed and/or natural processes. Wetlands are globally distributed ecosystems found on the coastal margins of many saltwater and freshwater ecosystems. These environments are characterized by distinct vegetation and the presence of hydric soils (Deil, 2005). Wetlands provide myriad benefits to both terrestrial and aquatic environs such as bank stabilization, wildlife habitat, flood attenuation, and water storage and purification. Different types of wetland biota are capable of removing different water contaminants including particulate matter, excess nutrients, metals, and other contaminants (Crites et al., 1997; Wu et al., 2001, 2011). Nutrients, including nitrate, phosphate and/or ammonia, can be filtered out by the plants and microorganisms present in the wetlands (see Figure 1). Plants can uptake nitrogen-containing compounds (including nitrates, nitrites and ammonium) and heavy metals into their roots (Delwiche, 1970). Any ammonia that is not absorbed by plant roots are converted into nitrates through the action of soil microorganisms in a process known as nitrification. Denitrifying bacteria can then convert nitrate into atmospheric nitrogen. Certain microorganisms are capable of performing anaerobic ammonium oxidation (anammox) (Kuenen, 2008). In anammox, ammonium ions are converted directly into nitrogen gas and water. In addition, positively charged ammonium ion can bind to negatively charged soil, thus removing it from the water moving through the wetlands (Wu et al., 2001).

Previously, constructed wetlands have been shown to be effective in the removal of ammonia (Crites et al., 1997; Wu et al., 2011). These wetlands were free water surface wetlands where the water surface is exposed to the atmosphere. The available oxygen allows nitrification to occur (Dennett and Spurkland, 2002; Wu et al., 2001). Given the need to bring natural processes into a science classroom and the fact that constructed wetlands can 

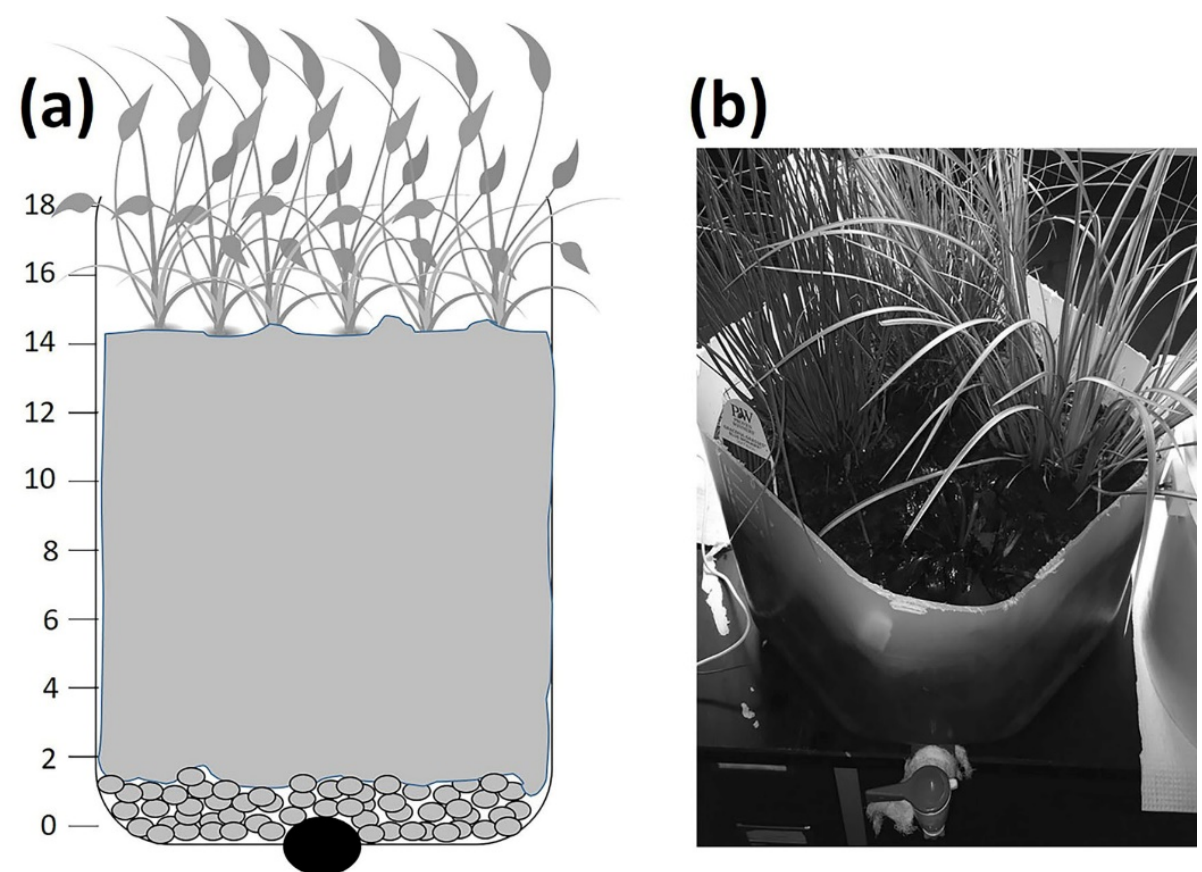

Figure 2. Construction of the wetlands filter in a 20 liter carboy. (a) A cross-section of the filter with stopcock (black oval). A layer of pebbles (gray ovals), followed by a mixture of top soil and mulch (gray) with wetland plants is added to the carboy. Numbers indicate volume (in liters). (b) Finished product of the wetlands filter.

effectively remove pollutants, we constructed a miniature freshwater wetland filter that can be established and maintained in a science classroom. This filter is capable of removing ammonium from water. In this paper, we describe how the wetlands filter was designed and how it is employed in our classroom.

\section{CONSTRUCTION AND TESTING OF WETLANDS MICROCOSM}

\section{Construction}

The wetland filter (see Figure 2) was constructed in a 20-liter polypropylene carboy. The top of the carboy was removed. Cheesecloth was placed behind the stopcock to reduce the amount of soil and particulate matter in the filtrate. Approximately 1 liter of Vigoro pea pebbles were added to bottom of the carboy. This layer was covered by a mixture of $15 \%$ mulch, $50 \%$ sand, 30\% top soil and 5\% moss to a total volume of 12 liters. We then planted various wetland plants, including Acorus sp., Carex sp., Lobelia sp., and Juncus sp. (Home Depot ${ }^{\circledR}$ and Plant Delights Nursery, Inc). Other wetlands plants could be utilized ("Wetlands Species," n.d.). The wetland was given 1 liter of deionized water as needed to keep the soil moist. The wetlands was kept under fluorescent lighting in the laboratory, mimicking the natural environment. We did not experiment on the wetland for one week to allow for root and soil microbe development.

To confirm that our wetland filter could remove ammonium ions from water samples, we poured a solution of $4 \mathrm{ppm}$ ammonium sulfate into the filter. Acceptable environmental limits for ammonia in surface water are between 0.25 - 32.5 ppm (US EPA 2019, Oregon 2000, Water Quality 2019). Currently, neither the US Environmental Protection Agency nor the World Health Organization define a maximum contaminant level for ammonia. We chose a concentration that would be higher than $0.25 \mathrm{ppm}$ and within the range of detection for our indicator. Prior to adding the ammonium sulfate, we drained the filter of standing water through the stopcock. After adding the ammonium sulfate solution, every 15 minutes over the course of two hours, five milliliter water samples were collected by opening the stopcock and collecting the filtrate. A total of 8 samples were collected. The samples were tested for ammonium ions using the API Ammonia Test Kit (Mars®Fishcare). Over the course of two hours, filtrate ammonium concentration decreased relative to the initial solution (see Figure 3). This suggests that our wetland microcosm is able to filter out ammonia from water. We additionally tested the filtrate for nitrate and nitrite using API Test Kits (Mars®Fishcare). Neither ion was detected (data not shown). 


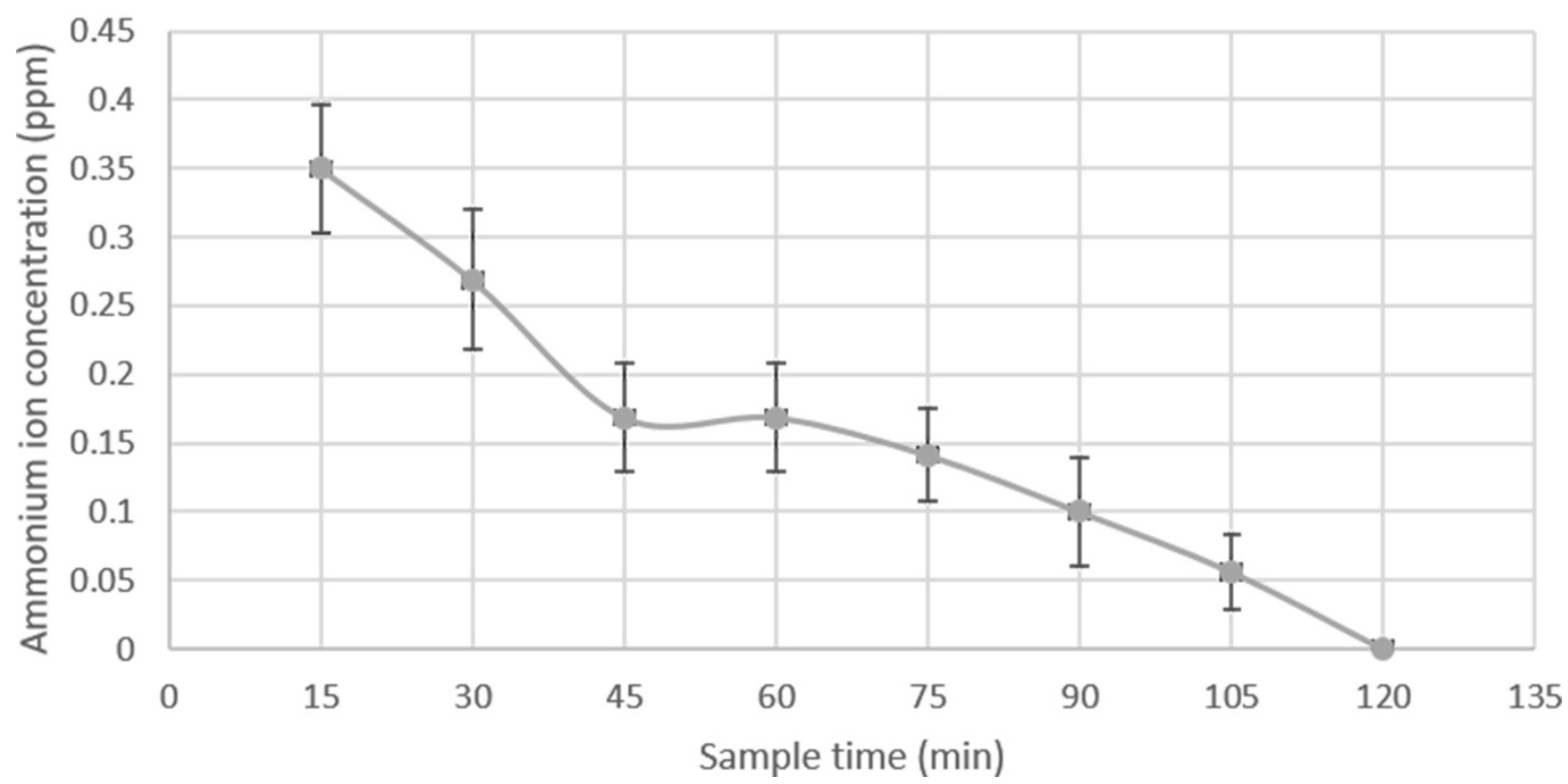

Figure 3. Detection of filtrate ammonium ions in filtrate over time. A 4 ppm ammonium sulfate solution was added to the filter. Every 15 minutes, the filtrate was tested for ammonium ions. Experiment was performed in triplicate. Average results are presented. Error bars indicate standard errors of the mean.

\section{WETLAND DEMONSTRATION}

\section{Demonstration Objectives \& Audience Pre-Requisites for Student Knowledge}

We have presented the constructed wetland microcosm demonstration to non-science majors during a laboratory lesson on water quality. Water quality testing provides the basis for determining potability, ecosystem health, and potential threats to resident organisms. In this lesson, students learn how to test water for pollutants, detect invertebrates and bacteria in water samples, and then determine what substrates effectively remove aquatic contaminants.

The main objectives of the wetland microcosm demonstration are for students to learn that: (a) an ecosystem is comprised of both biotic and abiotic factors; (b) how natural ecosystems function through biogeochemical cycles; and (c) that wetlands function as a natural filtration system to improve water quality. Prior to the start of the demonstration, students should be familiar with the nitrogen cycle. Specifically, students should be familiar with the role of microorganisms in nitrification, denitrification, and anammox. Students should also be familiar with the identities of various water pollutants and their sources, and the role that wetlands can play in removing these pollutants. Students should understand how to identify these pollutants in water samples (via colorimetric indicator test kits).

\section{Lesson \& Learning Time}

The class is given 2 liters of $4 \mathrm{ppm}$ ammonium sulfate. However, the students are not informed of the concentration. Each lab group in the class is given a 5 milliliters sample of the solution to quantify the initial ammonium concentration. The remaining ammonium sulfate solution is then poured into the wetland microcosm. After 2 hours (or longer if needed depending upon class' time and schedule), each lab group collects 5 milliliters of the filtrate. Students then measure ammonium concentration of both the initial solution and the wetland filtrate using an API ammonia test kit. Following the lesson, the students are then asked several questions (see Table 1).

\section{Advanced Science Classes - Bacteria Sequencing}

For advanced science-major classes, the DNA of wetland microcosm soil bacteria can be sequenced. To do so, genomic DNA can be isolated from the soil using a PowerSoil ${ }^{\circledR}$ DNA Isolation Kit (MoBio). The 16S rRNA gene can be amplified using PCR as described previously (Weisburg et al., 1991). The 1500 base pair PCR product can then be cloned into the pGEM plasmid, and clones selected for sequencing. The DNA sequences can be identified using BLAST analysis through the National Center for Biotechnology Information (NCBI) (Altschul et al., 1990). Based on these results, students could then be asked to explain how the wetland microbes they identified participate with the nitrogen cycle and contribute to the wetlands' ability to improve water quality. 
Pedagogical Research, 4(4), em0046

Table 1. Assessment questions following wetlands demonstration

\begin{tabular}{|c|c|}
\hline Objective & Question(s) \\
\hline (a) Ecosystem definition & - Examine the wetlands. Identify two biotic and abiotic components. \\
\hline (b) How ecosystems function & $\begin{array}{l}\text { - What was the initial concentration (in ppm) of ammonium ion entering the wetland? What } \\
\text { was the final concentration (in ppm)? Was the wetland able to remove ammonium ions? } \\
\text { - Relate your results to the nitrogen cycle. }\end{array}$ \\
\hline (c) Wetlands acting as a filter & $\begin{array}{l}\text { - Discuss a wetland's importance as a protectors of water quality. } \\
\text { - What other water pollutants would be able to be removed by a wetland? } \\
\text { - What water pollutants would not be able to be removed by a wetland? }\end{array}$ \\
\hline
\end{tabular}

Table 2. 16S rRNA gene sequencing results

\begin{tabular}{lc}
\hline 16S rRNA Sequence Isolated & Identity \\
\hline NNNNNNNNNNNNNNGGNCGATTGGGCCCGACGTCGCATGCTCCCGGCCGCCATGGCCGCGGGATT & Verrucomicrobia
\end{tabular}
AGAGTTT'TATCCTGGCTCAGAACGAACGCTGGCGGCGTGGATAAGACATGCAAGTCAAACGGGAGC GGTTTTTCAGCAATGGAAAACGCTCAAGTGGCAAACGGGTGCTTAACACGTAGATAATCTCCTGCGAG GATGGGAACAACCTGCTGAAAAGCAAGCTAATGCCCAATGTGATATTAGTGATCATTTTTCTAATCTCA AAGCCGGGGACTTTACAGCCTGGCGCCTTGCAATGAGTCTGCGGCCTATCAGCTAGTTGGTGAGGTA ATGGCTCACCAAGGCTACGACGGGTAGCTGGTCTTAGAGGACGACCAGCCACACTGGAACTGAGACA CGGTCCAGACACCTACGGGTGGCAGCAGTCGAGAATTTT'T'TCACAATGGGCGAAAGCCTGATGGAGCG ACGCCGCGTGGGGGATGAATGGCTTAGGCTTGTAAACCCCTGTCATTTGTGATCAAACAACGGCAGA TTAACAAGTTGCCGTTGAGATAGTAGCAAAAGAGGAAGAGACGGCTAACTCTGTGCCAGCAGCCGCG GTAATACAGAGGTCTCAAGCGTTGTTCGGATT'TACTGGGCGTAAAGGGTGCGTAGGCGGCAATTAAA GTTGCTGGTAAAATGGCCAAGCT'TAACTTGGTGTTGGCTAGCAATACTTAAATGCTGGGGAACCGAA TGGGAAACTGGAATTCTCGATGTAGCAGTGAAATGCGTAGATATCGAGAGGAACATCAGTGGCGAAA GCGAGTTTCTGGGCGGATTCCGACGCTGANGCACGAAAGCGAAGGTAGCAAACGGGATTAGATACC CCGGTAGTCTTCGCTGTAAACGGTGCTCACTAGCTGTGAGCGGTGTCAAATCCGCTCGTGGCGAAGT TAACACATTAAGTGAGCCGCCTGGGAAGTACGGCCGCAAGGCTAAAACTCAAGAAATTGACGGGGGC CTGCACAAGCGGTGGANTATGTNGCTTANNCGATGCAACGCGAANAACCT'TACCTAGTCTTGACNTT TANAATAGTAATTGTN

NNNNNNNNNNNNNGGGCGATTGGGCCCGACGTCGCATGCTCCCGGCCGCCATGGCCGCGGGATTA Acidobacteriales CGGCTACCTTGTTACGACTTCACCCCAGTCGCTGACCTTACCGTGGACGGCTGCCTCCTTGCGGTTAGC GCACCGGCTTAAGGTAAAACCAACTCCCATGGTGTGACGGGCGGTGTGTACAAGGCCCGGGAACGTA TTCACCGTGGCATGCTGATCCACGATTACTAGCGATTCCACCTTCATGCACCCGAGTTGCAGAGTGCA ATCTGAACTGAGACAGCTT'TTTAGGATCGGCTCGGGGTCGCCCCTTTGCATCCCATTGTCACTGCCATT GTAGCACGTGTGTAGCCCAGCCCGTAAGGGCCATGAGGACTTGACGTCATCCCCACCTTCCTCCGGTT TGTCACCGGCAGTCTCT'TCAGAGTGCCCGGCATAACCCGATGGCAACAGAAGACAAGGGTTGCGCTC GTTGCGGGACTTAACCCAACATCTCACGACACGAGCTGACGACAGCCATGCAGCACCTCTACAGACGT CCTTGCGGAAGCCTACTTTCGTAGGATGTCATCTGCAGTTCAAGCCTGGGTAAGGTTCTTCGCGTTGC GTCGAATTAAACCACATGCTCCACCGCTTGTGCGGGCCCCCGTCAAT'TCCT'TTGAGT'TTCAGCCTTGCG ACCGTACTCCCCAGGCGGAATGCTTAATGCGTTAGCTTCGGCACGGCAGGGATCGATACCCGCCACAC CAAGCATTCATCGT'TTAGGGCCAGGACTACCGGGGTATCTAATCCCGTTTGCTCCCCTGGCTTTCGCG CCTCAGCGTCAATACCGGTCCAGGATGTCGCCTTCGCCACCGGTGTTCCTCCAGATATCTACGCATTTC ACCGCTACACCTGGNANT'TCCACATCCCTCTCCCGGATTCGAGCCT'TCCAGTATCGGANGCAGTTCCC GGGTTTGAGCCCGGGGAT'T'TCACGTTCGACTGANAAGGCCGCCTACGCGCCCTTTTACGCCCAGTANNN ACANGCTTGCCCCNNTGNANTACCGCGGCTGCTGGCACAGAGTTAGCCGGGGCTNCNN

NNNNNNNNNNNNANGNCGATTGGGCCCGACGTCGCATGCTCCCGGCCGCCATGGCCGCGGGATTA Planctomycetes CGGCTACCTTGTTACGACTTAGCCCCAATCACCGGCCTTACCTTAGGCGCCTCCGTCCTTGCGGTTCGG TCGGCGACTTGGGATACCCCTCCCTTTCGTGGCTTGACGGGCGGTGTGTACAAGGCTCAGGAACACA TTCACCGCAGCATAGCTGATCTGCGATTACTAGCGATTCCAGCTTCATCCAGGCGAGTTGCAGCCTGC AATCCGAACTGAGCTGCGCTT'TTTTGGGATTGGCTCCCCCTCGCGGGTTGGCTTCCCTTTGTACGCAGC ATTGTGGCACGTGTGCAGCCCTAGACATAAAGGCCATGATGACTTGACGTCGTCCCCGCCTTCCTCCG GTTTGACACCGGCGGTCTCGCCAGAGTCCCCAACTAAATGCTGGCAACTGGCGACAGGGGTTTCGCT CGTTTAAGGACTTAACCCGACACCTCACGGCACGAGCTGACGACAGCCATGCAGCACCTGTGCAAGTT CCACCCGAAGGCGTCACCTGGCTTTCACCAGGCTAATCCTTGCATGTCAAGTCTAGGATAAGGTTCTTC GCGTTGCCTCGAATTAAGCCACATGCTCCACCGCT'TGTGTGAGCCCCCGTCAATTCCTTTGAGTTTCAG CCTTGCGACCATACTCCCCAGGCGCAGAACTTAACGCTTTCGCTACGACCGATGGGGGCGAACCCTCA TCCGTCCAGTTCTGATCGTTTACAGCCAGGACTACCGGGGTATCTAATCCCGTTTGGCTCCCCTGGCTTT CGTGCCTCAGCGTCAGACAAGCTCCAGTATGCCGCTTTCGCCTCTGGTGTTCCTTCCGATATCAACACA T'TTCACCGCTCCACCGGAAGT'TCCGCATACCTCTAGCTCACTCCAGCAATGCAGT'T'TCAAGCGCTGTTC CACGGGTTGAGCCGNNNCTTTCACACCTGACTTGCATCNCNCCTACGCACCCTGTAAGCCCAGTGATT CCGAATNACGTTCGCACAG

For classes that are unable to sequence the DNA from their own wetland soil, we provide the DNA sequences isolated from our wetland microcosm (see Table 2). As seen in Table 2, Sequence results identified bacteria from the Acidobacteria, Planctomycetes, and Verrucomicrobia phyla. It is interesting that the phyla we detected has been previously found in various wetlands, including freshwater (Hartman et al., 2008; Zhang et al., 2014) and acidic 
freshwater wetlands (Dedysh et al., 2006; Ivanova and Dedysh, 2012; Kulichevskaya et al., 2006). It has been reported that although Acidobacteria can use various sources of nitrogen, including ammonia, nitrate, nitrite and amino acids (Eichorst et al., 2018), there is no direct evidence for their participation in key nitrogen cycle reactions (Kielak et al., 2016). Several members of the Planctomycetes phylum are able to perform anammox (van Niftrik and Jetten, 2012). Isolates of Verrucomicrobia demonstrate nitrogen-fixing activity and contain genes for nitrogen fixation (Wertz et al., 2012). We did not detect any nitrifying or denitrifying bacteria. This is most likely because we only collected soil from one part of the microcosm at only one time point.

\section{CONCLUSION}

The instructional science laboratory is an important pedagogical environment (Hofstein and Lunetta, 2003). Students learn more when concepts can be presented either as an experiment or as a demonstration (Eick and King Jr, 2012). We believe designing and utilizing this constructed wetland microcosm allows students to observe for themselves the importance of wetlands in terms of water quality. This bridges the gap between what students (particularly non-science majors) learn in class with the natural systems we are teaching them. The construction of the filter is rather simple and can be easily employed in any science laboratory classroom.

\section{ACKNOWLEDGEMENT}

We would like to acknowledge Jonathan Violin and Jonathan Fingerut for the help in designing the filter. We thank Catalina Arango Pinedo for her help with the 16S rRNA gene sequencing. We also thank Caitlin Fritz, Clint Springer, Brian Kron and Thomas Smith for allowing us to test this laboratory exercise in their lab classes. We finally acknowledge Danielle Zabielski for her work in preparing Figure 1 and Kristen Chorney for her critical reading of this manuscript.

\section{Disclosure Statement}

No potential conflict of interest was reported by the authors.

\section{REFERENCES}

Altschul, S. F., Gish, W., Miller, W., Myers, E. W. and Lipman, D. J. (1990). Basic local alignment search tool. Journal of Molecular Biology, 215(3), 403-410. https://doi.org/10.1016/S0022-2836(05)80360-2

Crites, R. W., Dombeck, G. D., Watson, R. C. and Williams, C. R. (1997). Removal of Metals and Ammonia in Constructed Wetlands. Water Environment Research, 69(2), 132-135. https://doi.org/10.2175/106143097X1252 72

Dedysh, S. N., Pankratov, T. A., Belova, S. E., Kulichevskaya, I. S., and Liesack, W. (2006). Phylogenetic analysis and in situ identification of bacteria community composition in an acidic Sphagnum peat bog. Applied and Environmental Microbiology, 72(3), 2110-2117. https://doi.org/10.1128/AEM.72.3.2110-2117.2006

Deil, U. (2005). A review on habitats, plant traits and vegetation of ephemeral wetlands-a global perspective. Phytocoenologia, 35(2-3), 533-706. https:// doi.org/10.1127/0340-269X/2005/0035-0533

Delwiche, C. (1970). The Nitrogen Cycle. Scientific American, 223(3), 136-147. https://doi.org/10.1038/scientificamerican0970-136

Dennett, K. E. and Spurkland, L. E. (2002). Using Constructed Wetlands to Improve Water Quality and Reduce Nonpoint Pollutant Loadings into the Truckee River. Proceedings of the Water Environment Federation, 2002, 822835. https://doi.org/10.2175/193864702784163191

Eichorst, S. A., Trojan, D., Roux, S., Herbold, C., Rattei, T. and Woebken, D. (2018). Genomic insights into the Acidobacteria reveal strategies for their success in terrestrial environments. Environmental Microbiology, 20(3), 10411063. https://doi.org/10.1111/1462-2920.14043

Eick, C. J. and King Jr, D. T. (2012). Nonscience Majors' Perceptions on the Use of YouTube Video to Support Learning in an Integrated Science Lecture. Journal of College Science Teaching, 42(1), 26-30. Retrieved from http://www.jstor.org/stable/43748401

Ernst, J. and Theimer, S. (2011) Evaluating the effects of environmental education programming on connectedness to nature. Environmental Education Research, 17(5), 577-598. https://doi.org/10.1080/13504622.2011.565119

Hartman, W. H., Richardson, C. J., Vilgalys, R. and Bruland, G. L. (2008). Environmental and anthropogenic controls over bacterial communities in wetland soils. Proceedings of the National Academy of Sciences of the United States of America, 105(46), 17842-17847. https://doi.org/10.1073/pnas.0808254105 
Hofstein, A. and Lunetta, V.N. (2003). The laboratory in science education: Foundations for the twenty-first century. Science Education, 88(1), 28-54. https://doi.org/10.1002/sce.10106

Ip, Y. K., Chew, S. F. and Randall, D. J. (2001). Ammonia toxicity, tolerance and excretion. Fish Physiology. https:// doi.org/10.1016/S1546-5098(01)20005-3

Ivanova, A. O. and Dedysh, S. N. (2012). Abundance, Diversity, and Depth Distribution of Planctomycetes in Acidic Northern Wetlands. Frontiers in Microbiology, 3, 5. https://doi.org/10.3389/fmicb.2012.00005

Joyce, S. (2000). The dead zones: oxygen-starved coastal waters. Environmental Health Perspectives, 108(3), A120A125. https://doi.org/10.1289/ehp.108-a120

Kielak, A. M., Barreto, C. C., Kowalchuk, G. A., van Veen, J. A. and Kuramae, E. E. (2016). The Ecology of Acidobacteria: Moving beyond Genes and Genomes. Frontiers in Microbiology, 7, 744. https://doi.org/10.3389/fmicb.2016.00744

Kuenen, J. G. (2008). Anammox bacteria: from discovery to application. Nature Reviews Microbiology, 6, 320-326. https://doi.org/10.1038/nrmicro1857

Kulichevskaya, I. S., Pankratov, T. A. and Dedysh, S. N. (2006). Detection of representatives of the Planctomycetes in Sphagnum peat bogs by molecular and cultivation approaches. Microbiology, 75, 329-335. https://doi.org/10.1134/S0026261706030155

Lee, Y. W. and Kim, G. (2007). Linking groundwater-borne nutrients and dinoflagellate red-tide outbreaks in the southern sea of Korea using a $\mathrm{Ra}$ tracer. Estuarine, Coastal and Shelf Science, 71(1-2), 309-317. https://doi.org/10.1016/j.ecss.2006.08.004

Oregon Department of Human Services. (2000). Ammonia Health Effects Information. Available at: https://www.oregon.gov/oha/PH/HealthyEnvironments/DrinkingWater/Monitoring/Documents/health/ ammonia.pdf (Accessed 14 August 2019)

Paul, M. J. and Meyer, J. L. (2001). Streams in the Urban Landscape. Annual Review of Ecology and Systematics, 32, 333-365. https://doi.org/10.1146/annurev.ecolsys.32.081501.114040

Pavlidis, G. and Tsihrintzis, V. A. (2018). Environmental Benefits and Control of Pollution to Surface Water and Groundwater by Agroforestry Systems: a Review. Water Resources Management, 32(1), 1-29. https://doi.org/10.1007/s11269-017-1805-4

Pearson, J. and Stewart, G. R. (1993). The deposition of atmospheric ammonia and its effects on plants. New Phytologist, 125, 283-305. https://doi.org/10.1111/j.1469-8137.1993.tb03882.x

Roy, A. H., Rosemond, A. D., Paul, M. J., Leigh, D. S. and Wallace, J. B. (2003). Stream macroinvertebrate response to catchment urbanisation (Georgia, U.S.A.). Freshwater Biology, 48(2), 329-346. https:/ / doi.org/10.1046/j.13652427.2003.00979.x

Smith, V. H., Tilman, G. D. and Nekola, J. C. (1999). Eutrophication: impacts of excess nutrient inputs on freshwater, marine, and terrestrial ecosystems. Environmental pollution, 100(1-3), 179-196. https://doi.org/10.1016/S0269-7491(99)00091-3

Smith, W. S., Gould, S. M. and Jones, J. A. (2004). Starting the Semester at Odds: Educators' Versus Students' Reasons for Studying Science. Journal of College Science teaching, 34(4), 44-49. Retrieved from http://www.jstor.org/stable/42992356

United Nations (UN). (2012). Managing Water under Uncertainty and Risk. World Water Development Report 4. Paris: UNESCO Publishing. Available at: http://unesdoc.unesco.org/images/0021/002156/215644e.pdf

United States Environmental Protection Agency. (2019). Aquatic Life Criteria - Ammonia. Available at: https://www.epa.gov/wqc/aquatic-life-criteria-ammonia (Accessed 14 August 2019)

van der Eerden, L. J. M. (1982). Toxicity of ammonia to plants. Agriculture and Environment, 7(3-4), 223-235. https://doi.org/10.1016/0304-1131(82)90015-7

van Niftrik, L. and Jetten, M. S. M. (2012). Anaerobic Ammonium-Oxidizing Bacteria: Unique Microorganisms with Exceptional Properties. Microbiology and Molecular Biology Reviews, 76(3), 585-596. https://doi.org/10.1128/MMBR.05025-11

Water Quality Association. (2019). Ammonia. Available at: https://www.wqa.org/learn-about-water/commoncontaminants/ammonia (Accessed 14 August 2019)

Weisburg, W. G., Barns, S. M., Pelletier, D. A. and Lane, D. J. (1991). 16S Ribosomal DNA Amplification for Phylogenetic Study. Journal of Bacteriology, 173(2), 697-703. https://doi.org/10.1128/jb.173.2.697-703.1991

Wertz, J. T., Kim, E., Breznak, J. A., Schmidt, T. M. and Rodrigues, J. L. (2012). Genomic and physiological characterization of the Verrucomicrobia isolate Geminisphaera colitermitum gen. nov., sp. nov., reveals microaerophily and nitrogen fixation genes. Applied and Environmental Microbiology, 78(5), 1544-1555. https:// doi.org/10.1128/AEM.06466-11

Wetlands Species. (n.d.). Available at: https://www.wetlandplantsinc.com/species (Accessed 14 August 2019) 
Wu, H., Zhang, J., Li, P., Zhang, J., Xie, H. and Zhang, B. (2011). Nutrient removal in constructed microcosm wetlands for treating polluted river water in northern China. Ecological Engineering, 37(4), 560-568. https://doi.org/10.1016/j.ecoleng.2010.11.020

Wu, M., Franz, E. and Chen, S. (2001). Oxygen Fluxes and Ammonia Removal Efficiencies in Constructed Treatment Wetlands. Water Environment Research, 73(6), 661-666. https://doi.org/10.2175/106143001X143394

Zhang, J., Zhang, X., Liu, Y., Xie, S. and Liu, Y. (2014). Bacterioplankton communities in a high-altitude freshwater wetland. Annals of Microbiology, 64(3), 1405-1411. https://doi.org/10.1007/s13213-013-0785-8 